\title{
A Review of Research Status and Prospect of Vacuum Insulated Tubing Insulation System
}

\author{
Xing Yu*, Liu Lei, Cao Chang, Fan Weidong, Yan Keju,Cheng Zhongfu \\ Sinopec Northwest Oil Field Company, Wulumuqi 830011, China
}

\begin{abstract}
Vacuum heat insulating tubing is an important wellbore heat insulating facility for heavy oil thermal recovery at present. Its heat insulating performance directly affects the thermal recovery efficiency. The research on the heat insulating system of vacuum heat insulating tubing is of great significance to improve and improve the heat insulating performance and enhance the thermal recovery of heavy oil. This paper summarizes and analyses the current research status of vacuum insulated tubing insulation system. It elaborates the insulation structure, insulation materials, annular air charging and vacuum pumping, insulation coating and so on. It provides reference and reference for the future research of vacuum insulated tubing.
\end{abstract}

Keywords :vacuum insulated tubing; thermal insulation; review

\section{Introduction}

Insulated tubing is a professional string for thermal recovery of heavy oil, and is one of the necessary downhole tools for heavy oil thermal recovery. Steam injection through insulated tubing can bring more heat into the reservoir and improve the dryness of steam reaching the bottom of the well, thus gaining the effect of heavy oil development and production increase [1]. It is of great significance to carry out the research on steam flooding heat insulation tubing for promoting the development of steam flooding heavy oil thermal recovery technology and the long-term development of enterprises $[2,3]$. Vacuum insulating tubing is the most effective insulating technology in the world, so it is also called "super insulating technology" (VIT). On the basis of investigating the domestic and foreign literature on heat-insulating tubing, this paper analyses and summarizes the research on heat-insulating structure system and material of heat-insulating tubing, and looks forward to the future research prospects.

\footnotetext{
* Corresponding author: Li964499@126.com
} 


\section{Domestic vacuum insulation tubing research status}

At present, the main manufacturers of heat insulation oil pipes in China are Liaohe Petroleum Exploration Bureau General Machinery Factory, Shengli Oilfield Furuite Petroleum Equipment Co., Ltd., Jiangsu Yancheng Jinfeng Petroleum Machinery Company and Wuxi Simles Steel Pipe Co., Ltd. Liaohe Petroleum Exploration Bureau General machinery plant is the largest manufacturer of vacuum insulation tubes in China [4].

In the study of the effect of vacuum on the thermal insulation performance of vacuum insulated tubing in the General Machinery Factory of Liaohe Petroleum Exploration Bureau, it is pointed out that pumping the internal pressure of the insulating layer into (30-40) $\mathrm{Pa}$ compartments is very helpful to ensure the thermal insulation performance of the insulating tubing and control the production cost of the insulating tubing[5].

In the study of improving the wellbore thermal insulation and cold production technology of low-cost insulated tubing in Shenyang Oil Production Plant, the strength of prestressing force and high temperature treatment on production tubing string is reduced. The vacuum degree is within an optimal range. The improved vacuum insulated tubing has been in well time for half a year, and its apparent thermal conductivity is still in grade D, basically stable and applied. The service life can be increased to 3.5-4 years. In order to ensure the vacuum life of the insulating sleeve, special high temperature air-breathing materials are placed in the annulus. The technology of low cost vacuum insulated tubing is applied in 38 wells, and the total electricity saving is $542.68 \times 104 \mathrm{~kW}$. $\mathrm{h}[6]$.

In the research and application of high condensate oil cold production technology in Shenyang Oilfield, the selected target well is $67-563$, which is produced by $1200 \mathrm{~m}$ vacuum heat insulation tubing. For oil wells with 18 tons of liquid per day, the wellhead temperature can be increased by $10-13{ }^{\circ} \mathrm{C}$, and the outlet temperature can reach $37{ }^{\circ} \mathrm{C}$, which can achieve the purpose of cold production; $1600 \mathrm{~m}$ vacuum heat insulation tubing can be used to maintain the wellhead temperature. Temperature production can increase wellhead temperature by $12-15{ }^{\circ} \mathrm{C}$ for oil wells with daily liquid production of more than 16 $\mathrm{t}$, and due to the temperature of wellhead liquid production reach about $37{ }^{\circ} \mathrm{C}$, so as to achieve the goal of cold production [7].

In the numerical simulation analysis of the thermal insulation effect of foam glass insulated tubing and vacuum heat insulated tubing, the Chinese Academy of Sciences and CNOOC Research Institute have found that before the hydrogen permeation, both the vacuum insulated tubing and the foam glass heat insulation oil pipe can achieve good thermal insulation effect. However, after the hydrogen permeation, the heat flux density of the vacuum insulated tubing is urgent. The increase of the theater result in the failure of the vacuum insulated tubing and the increase of heat flux density after the hydrogen permeation of the foam glass insulating oil pipe is not obvious. When the thickness of the insulation layer of the foam glass heat insulation pipe reaches $16 \mathrm{~mm}$, the heat flux density of the foam glass insulation tube is actually equivalent to that of the vacuum insulation tube before failure[8].

The Research Institute of China National Offshore Oil Corporation has put forward a heat insulation technology which combines thermal insulation coating with vacuum technology[9]. The main design method of this process is: heat insulation coating treatment of the outer wall of the insulating oil pipe, high temperature and high pressure packer is placed in the designated position of the casing annulus, vacuum pump is used to vacuum 
the casing annulus through the casing wing valve of the oil production tree, and heat injection operation can be started after meeting the requirements (vacuum is installed on the casing wing valve). The vacuum degree of oil sleeve annulus can be monitored during the injection heat, and the vacuum can be supplemented according to the requirement.

Shengli Oilfield has developed the fourth and fifth generation heat insulating pipes, hydrogen-proof heat insulating pipes and vacuum heat insulating pipes, which have entered the field use and test stages respectively [10]. Under the condition of steam injection at 325 ${ }^{\circ} \mathrm{C}$, the apparent thermal conductivity of the vacuum insulating pipe is still $0.008 \mathrm{~W} /(\mathrm{m} . \mathrm{K})$ after three cycles of test. The anti-hydrogen damage insulating pipe produced by new hydrogen absorbent can double the service life of the original insulating pipe and reach 30 huff and puff cycles. Steam injection string has been able to meet the needs of different heat insulation requirements for 200-1700 m wells, especially for $800-1700 \mathrm{~m}$ deep wells. The wellbore heat loss can be controlled within $12 \%$ by using high efficiency heat insulation pipe, high temperature separator, expansion pipe and annulus filled with nitrogen gas. The heat insulation performance has exceeded that of the products imported from abroad in the late 1980s.

\section{Foreign research on vacuum insulated tubing}

At present, the technology of high-efficiency heat preservation and insulation abroad is relatively mature, and the technology of vacuum heat insulation tubing is widely used in the world. The application of VIT in Troika Oilfield in Britain keeps the fluid in the wellbore at a higher temperature and reduces energy consumption; the high-efficiency heat insulation pipe used in Kern River Oilfield in the United States reduces the energy loss of the wellbore by about 5\%; the heat insulation tubing has been applied in actual production in Gulf of Mexico ${ }^{[11]}$ and offshore oil field in Brazil ${ }^{[12]}$.

The VIT produced by ConocoPhillips is successfully applied to in waxy crude oil extraction technology under arctic environment [6]. In the wellbore of deep water oil field in Gulf of Mexico, VIT has been successfully used for heat insulation, solving the problems of paraffin deposition and hydrate blockage, which hinder the flow of well fluid. In the tubing of Norman well, VIT can greatly reduce the radial heat transfer of wellbore and solve the problem of paraffin deposition in inner tubing.

VIT has been widely used in steam injection wells in onshore oilfields in northeastern and southeastern Brazil [13]. It has also been tried in offshore well production. The structure sketch and details of connection are shown in Fig. 1. 


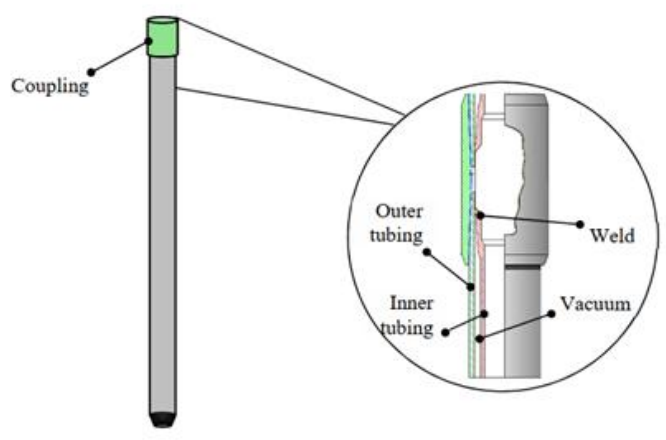

Fig.1. Vacuum insulated tubing concept and detail of the connection region.

Exceed High Thermal Efficiency Tubing (HTET) manufactured by Exceed oilfield equipment Company of Canada uses new nano-insulation materials, which can reduce steam heat loss, maintain steam quality, reduce casing deformation and protect cement casing. Canada also has a new type of heat insulating tubing called T-IMEX. Unlike the traditional VIT, IMEX has only one leakage path, which further reduces heat loss. The structure and details of HTET are shown in Figure 2.

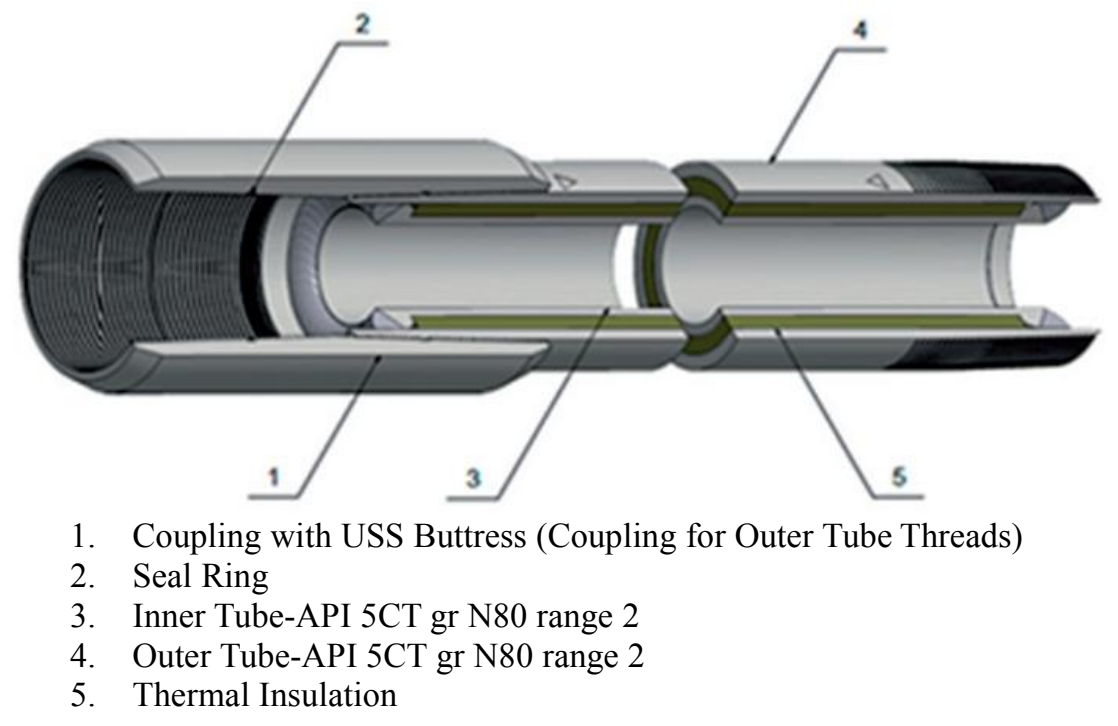

Fig.2. Vacuum insulated tubing concept and detail of the connection region.

T Śliwa [14] studied the application of vacuum insulated tubing in deep well heat exchangers. The biggest problem in the production and development of VIT is hydrogen permeation. This process affects the insulation efficiency and increases the heat transfer through the inner column. Hydrogen is easily penetrated into most steel materials. Absorbent is a good absorbent to absorb hydrogen through the vacuum ring. Therefore, 
before installation of VIT, the amount of absorbent material and potential hydrogen permeation need to be studied through field test or laboratory research.

In 2015, at the SPE Hot Well Integrity and Design Symposium held in Banff Alberta, Canada, J. Damour and other scholars introduced their work on steam flow in a project in the Middle East. The design and economic considerations of selecting VIT or VIC in hot well completion are introduced. J. Damour summarized the main failure modes of oil well integrity: casing expansion and the resulting load, cement integrity under thermal cycling, annulus pressure accumulation. In the BP MARLIN project, production casing collapsed due to annular pressure, resulting in well loss [15]. The drill string of Pomp.A-31 well in the Gulf of Mexico was distorted by annular pressure, which caused 16 inch casing stuck [16]. At the same time, the seabed wellhead prevented deep water wells from releasing annular pressure in casing annulus, which is different from the onshore wells and platform wells. In addition, deepwater drilling accidents will not only cause huge economic losses, but also cause serious environmental pollution [17]. Therefore, scholars have provided a solution for evaluating VIT (or VIC) by thermal well models of casing and tubing temperatures in order to avoid well failure. The heat loss of different VIT products is given to measure the impact on the process efficiency and economy. Some parameters considered in the design of hot well are given: casing temperature, tubing temperature and heat loss. By determining these parameters, the integrity of the well can be studied, and the efficiency of the whole process is estimated to be [18]. They quantitatively analyzed the influence of thermal performance and tubing size on underground steam quality. The steam flow analysis model was used to compare the different diameter and heat insulation performance of the same well. The thermal performance (total heat transfer coefficient) of different types of heat insulation pipes is determined by the operator through field tests before being used as model input. The output of the model is the mass, temperature and pressure of the steam, which is a function of the well location (including downhole conditions). It is also found that under the optimal thermal performance, reducing the diameter of the pipe can have a positive impact on the economy of the system. On the contrary, it is found that it is impractical to reduce the size of pipes by using pipes with relatively poor thermal performance. The results can be used to select the type and size of the new syringe Wells tube. With the completion of the analysis, steam wells are being modified according to research proposals in the field of research. Vacuum heat insulation pipes are gradually replaced by design with improved thermal performance, and the size of the pipes is reduced, thus reducing the overall cost and improving the quality of downhole steam [19].

Rashid Al Shaibi (SPE 172930-MS) describes an experiment carried out by operators of the Middle East Heavy Oilfield in steam injection wells, in which heat insulation pipes from four different manufacturers are installed, in which temperature can be monitored by optical fibers and thermometers. The data collected during the experiment show that the vacuum insulation technology has the best effect on the joint: the overall thermal performance is the best, the thermal performance will not deteriorate over time, and the temperature difference between the joint and the joint body is the smallest. The three combinations that best represent the different solutions of oil wells are: (1) insulating pipes with 3103 1/2 inner pipes, which have standard thermal performance; (2) insulating pipes with $31031 / 2$ inner pipes, which have excellent heat dissipation performance; (3) 
insulating pipes with 2103 7/8 inner pipes, which have excellent heat dissipation performance. For each configuration, steam is injected at 572 degrees F (300 degrees C) with a mass of $85 \%$ at the wellhead[19].

Mirko Zatka of Shell Energy Canada presented a special report entitled "Application of Vacuum Thermal Insulation Pipe in Hot Oil Sand Engineering" at the SPE Heavy Oil Conference and Exhibition held in Kuwait City in 2016. The report traces the technical development history of VIT, introduces the manufacturing process of VIT and design elements affecting its long-term performance. How to determine the actual heat transfer coefficient of the product, and how to verify the real performance once the VIT is installed in the well, et. al. [20].

ITM and OTSI use proprietary software programs to calculate and predict bottomhole steam quality. Field tests by industry and the U.S. Department of Energy confirm the validity of software programs used to predict heat loss and bottomhole quality [21]. The test results show that compared with bare tube, vacuum insulation tube will greatly reduce heat loss and improve bottom hole steam quality. At 1,000 feet $(304.8 \mathrm{~m})$, the difference between insulated and non-insulated tubing is $13.6 \%$, increasing to $47.5 \%$ at 3,500 feet $(1066.8 \mathrm{~m})$. Checking the percentage of steam mass in each type of tubing, the researchers found that the steam mass of bare tubing decreased by $35.4 \%$ from 1000 to 3500 feet $(305-1067 \mathrm{~m})$, with the steam quality of insulated tubing almost unchanged.

Editor of Journal of Petroleum Technology (JPT) pointed out that the most common methods of thermal enhanced oil recovery are cyclic steam agitation, steam flooding and steam-assisted gravity drainage, which are widely used in Canada [22]. Typical steam injection temperatures are between 250 and 310 degrees Celsius, and may be greater than 310 degrees in a few cases. This high temperature application requires adjusting the design of injection wells to avoid any mechanical failure of wells or to reduce heat loss through wells. Vacuum insulation tube (VIT) or vacuum heat insulation casing (VIC) is a way to solve these problems. There are two main types of insulated tubing. The first type of VIT is based on the thermal insulation materials used in the aerospace industry. It needs high vacuum (10-5 Torr) to connect to multi-layer foil. The hydrogen leakage of carbon steel through pipeline increases the vacuum pressure in annular space. Therefore, the use of high vacuum leads to the decrease of the service life of VIT. Another kind of thermal insulation material is the microporous material used between the inner and outer pipes. The application of soft vacuum, usually 10 torus, reduces the heat transfer mode by reducing the average free path of the air molecules in the microporous material.

In comparing concentric and eccentric configurations of VIT and bare tubing, ANSYS Canada and ZEroCor Pipeline Company studied three different formation temperatures $(253.15 \mathrm{~K}, 313.15 \mathrm{~K}$ and $423.15 \mathrm{~K})$, two different tubing types (bare tubing and VIT tubing) and two different tubing configurations (concentric tubing and eccentric tubing). 12 simulations of were carried out [23]. On the other hand, the steam quality of VIT tubing is minimized at different formation temperatures. The vacuum insulation material of VIT can be used as a good insulation layer and keep heat in the pipeline. Under three different temperatures, the variation of steam mass is less than $1 \%$. Compared with bare tubes, the steam quality is saved by $4.6 \%$ on average. 


\section{Conclusions and prospects}

This paper summarizes and analyses the research on the thermal insulation structure system and material of vacuum insulated tubing at present, and summarizes the current research and development status. It can be seen from the research at home and abroad that vacuum insulated tubing is a widely used wellbore thermal insulation technology at present. Its product quality is reliable and its performance is stable, which makes its tubing body. The apparent thermal conductivity is reduced by one order of magnitude than the apparent thermal conductivity of the conventional insulating tubing. However, the heat flux density of vacuum insulating pipe after hydrogen permeation failure is very large, which is more than 10 times that before failure. In order to maintain its excellent heat insulation performance in the long-term steam injection process and achieve excellent heat insulation effect, it is necessary to inject getter in annulus, absorb $\mathrm{H} 2$ and other residual gases infiltrated into steel pipe during steam injection process, so as to make the heat insulation system. The system will be purified at any time to maintain the intact state of the vacuum system. From the point of view of technology and economy, vacuum insulated tubing has high price, complex structure and self-weight, which is not suitable for deep well operation. The research and development of new thermal insulation materials were predicted. It has remarkable effects on thermal insulation and thermal recovery, and is also the focus of future research.

\section{References}

[1] Bi Pu-yue, Liu Xin-tian. Application and analysis of thermal insulation technology for hot oil injection steam pipe network [J]. Chemical Engineering Design Communications, 2017, 43(12):61-61.

[2] Guo Qian. The research and application of composite insulation lining tubing technology[D]. Southwest Petroleum University, 2017:1-5.

[3] Zhang Xiao-hui. Preparation and Property of Thermal Insulation Coating on the Connection Between the Insulated Tubing[J]. materials protection 2018, 51(2): 82-84.

[4] Sun Cheng-li. Development and application of insulated tubing used for heavy oil thermal production[D]. Northeast Petroleum University, 2014:2-6.

[5] Wu Yong-ning. The Vacuum Degree Impact on the Insulation Properties of Insulated Tubing[J]. Science Technology and Engineering, 2010, 10 (11): 2728 - 2732.

[6] Zhao Xu-guang, Wang Zhan-sheng. Research and application of low temperature heat insulation tubing shaft insulation technology[J]. Chemical Engineering Design Communications, 2017, 43(8):76-76.

[7] Guo Dao-hong. The study and application of nonthermal production technology of high pour point crude oil in Shenyang Oil Field[D]. Northeast Petroleum University, 2012:27-30.

[8] Zhou Cheng-long, Xu Yong-xiang, Sheng Hong-zhi, et. al. Numerical simulation analysis of thermal insulation effect of foam glass insulated tubing and vacuum insulated tubing[J]. Chemical Engineering \& Equipment, 2015(1):5-9. 
[9] Lin Tao, Zhang Wei, Zou Jian, et.al. Heat insulation coating and vacuum technology and its application in heavy oil thermal production[J]. Petroleum Geology and Engineering, 2016(5):127-129.

[10] Liu Jun-yan.Reesareh on improving steam thermal efficiency[D]. Southwest Petroleum University, 2003:35-44.

[11] S.W. Gosch, D.J. Horne, P.D. Pattillo, J.W. Sharp, P.C. Shah, Marlin failure analysis and redesign: part 3 - VIT completion with real-time monitoring, SPE Drill.Complet. 19 (02) (2004) 120-128.

[12] M.V.D. Ferreira, A.R. Dos Santos, V. Vanzan, Thermally insulated tubing application to prevent annular pressure buildup in Brazil offshore fields, SPE Deepwater Drilling and Completions Conference, Galveston, Texas, USA, June 20-21, 2012.

[13] Barcelos J G A, Ferreira M V D, Costa C A S, et al. Thermal analysis of vacuum insulated tubing (VIT) for offshore wells[C]// Brazilian Congress of Thermal Sciences and Engineering. 2014.

[14] Śliwa T, Kruszewski M, Sapińska-Śliwa A, et al. The application of Vacuum Insulated Tubing in Deep Borehole Heat Exchangers[J]. 2017, 34(2):597.

[15] D.W. Bradford, D.H. Gibson, S.W. Gosch, P.D. Pattillo, J.W. Sharp, C.E. Taylor,Marlin failure analysis and redesign: part 1 description of failure, IADC/SPE Drilling Conference, Dallas, USA, February 26-28, 2002.

[16] P.D. Pattillo, B.W. Cocales, S.C. Morey, Analysis of an annular pressure buildup failure during drill ahead, SPE Drill. Complet. 21 (04) (2006) 242-247.

[17] L.-G. Faksness, D. Altin, T. Nordtug, P.S. Daling, B.H. Hansen, Chemical comparison and acute toxicity of water accommodated fraction (WAF) of source and field collected Macondo oils from the Deepwater Horizon spill, Mar. Pollut. Bull. 9(01) (2015) 222229.

[18] Damour J, Johannson D. What Vacuum Insulated Tubings Or Vacuum Insulated Casings Bring To Thermal Wells[C]// SPE Thermal Well Integrity and Design Symposium. 2016.

[19] Damour J, Brown T. Downsizing Steam Injection Insulated Tubing through the Use of Superior Thermal Performance[C]// SPE Thermal Well Integrity and Design Symposium. 2015.

[20] Zatka M. Application of Vacuum-Insulated Tubing VIT in Thermal Oil Sand Projects[C]// SPE Heavy Oil Conference and Exhibition. 2016.

[21]Lombard, M. S., Lee, R., Manini, P., \& Slusher, M. S. New Advances and a Historical Review of Insulated Steam-Injection Tubing. [C]//SPE Western Regional and Pacific Section AAPG Joint Meeting. 2008.

[22]Carpenter, C. What Vacuum-Insulated Tubings and Casings Bring to Thermal Wells[J]. Journal of Petroleum Technology, 2017,69(06), 73-74.

[23]Karra, S., Chudiak, M., Sinha, A., \& Boser, G. SAGD Vacuum Insulated Tubing vs. Bare Tubing - Concentric and Eccentric Configurations: A Comparative Thermal Computational Fluid Dynamics Study. SPE Heavy Oil Conference-Canada. 2014. 